practitioners in the district in which he resides who are willing to see him for such a fee.

(d) A list of ophthalmic medical practitioners qualified and willing to see insured members of approved societies at a consultation fee of $£ 1$ 1s. should be prepared in accordance with the following principles:

(i) That he has held hospital or other appointments affording special opportunities for acquiring special skill and experience of the kind required for the performance of the service rendered, and has had actual recent practice in performing the service rendered or services of a similar character, or

(ii) That he has had special academic or post-graduate study of a subject which comprises the service rendered, and has had actual practice as aforesaid, or

(iii) That he is generally recognized by other practitioners in the area as having special proficiency and experience in a subject which comprises the service rendered.

(e) That a list be prepared of opticians who are willing to supply optical appliances prescribed by medical practitioners for insured members of approved societies in accordance with an agreed schedule of charges.

(f) In the event of the surplus funds of an approved society being insufficient to allow of its paying the specialist's reduced fee of $£ 1$ s. for consultation, the patient himself will be required to furnish any amount additional to that which the approved society is able to grant for this purpose.

These recommendations were approved by the Council and forwarded to the Ministry of Health, and a reply has been received from the Ministry stating that a small office committee has been appointed to consider the question.

\title{
ANNOTATION
}

\section{Undergraduate and Graduate Teaching in Ophthalmology}

IT is interesting to find from the appendix of the 1923 volume of the Transactions of the American Ophthalmological Society, that in the United States of America, as in this country, the subject of teaching ophthalmology to undergraduates and graduates has been receiving considerable attention. Readers of this journal will recollect that these matters formed the subject of two reports by the Council of British Ophthalmologists in 1919 (Brit. Jl. of Ophthal., Vol. III, pp. 165, and 558). 